\title{
MÁS ALLÁ DE LA ESTÉTICA: JORGE EDUARDO EIELSON FRENTE AL LEGADO PREHISPÁNICO ${ }^{(*)}$
}

\author{
BEYOND AESTHETICS: JORGE EIELSON AGAINST THE PRE-HISPANIC LEGACY
}

\author{
FRANCO CAVAGNARO FARFÁN ${ }^{[*]}$ \\ Fecha de recepción: 20 de marzo de 2017 \\ Fecha de aprobación: 19 de mayo de 2017
}

\begin{abstract}
RESUMEN
Realizando un recorrido por sus ensayos y su propia obra literaria, en este artículo se analiza y establece el contexto básico que lleva a Jorge Eduardo Eielson a la comprensión del legado. Para ello se hace una breve exposición de aspectos legales del patrimonio y la intuición poética del mismo a través de las ideas de otros escritores y artistas. Esta conciencia a su vez se contrapone con la posición tomada por Eielson en los años 80 a favor de una posición curatorial frente al patrimonio mueble. Adicionalmente, se hace evidente el entendimiento que el artista establecía con el pasado prehispánico. Para ello desde un enfoque multidisciplinario se analiza la iconografía y la arquitectura andina sobre las que el poeta escribía en sus ensayos; de este modo en el artículo se establece la intuición que Eielson había desarrollado desde su exilio, como una inversión de la monumentalidad italiana que se recrea en su poesía escrita en ese país. Es decir, a través de su acercamiento al pasado prehispánico, desconocido y/o despreciado, durante su vida en Lima, el artista realiza una revalorización espectacular desde el exilio.
\end{abstract}

\section{PALABRAS CLAVE}

Patrimonio inmueble, arte prehispánico, poesía peruana

\begin{abstract}
Through a journey of his essays and his own literary work, this article analyzes and establishes the basic context that pushed Jorge Eduardo Eielson to understand the pre-Hispanic legacy. For this purpose, it presents the heritage's legal aspects and his poetic intuition through the ideas of other writers and artists. This conscience acts in counterpoint to the position taken by Jorge Eduardo Eielson in the 1980s in favor of a curatorial position vis-à-vis heritage assets. In addition, the article makes the artist's understanding of the Pre-Hispanic past evident. Through a multidisciplinary approach, the Andean iconography and architecture about which the poet wrote about in his essay is analyzed. In such a way, the article establishes the intuition that Jorge Eduardo Eielson had developed from his exile, as an inversion of Italian monumentality and which is recreated in the poetry he wrote in that country. That is, through his approach to the Pre-Hispanic past, unknown and/or unappreciated, during his life in Lima, the artist puts forward a spectacular revaluation from exile.
\end{abstract}

\section{KEYWORDS}

Property heritage, pre-Hispanic art, Peruvian poetry

\footnotetext{
(*) Este artículo es una adaptación de una investigación para la aceptación de una maestría en la Universidad Católica de Chile (2015), que analiza la relación entre varios artistas peruanos y el legado prehispánico. Y se complementa con la novela, Huaquero (Una Historia sobre la Historia), la cual fue el primer paso hacia la comprensión del patrimonio de parte del autor.

(**) Licenciado en Literatura Hispánica por la Pontificia Universidad Católica del Perú. Ha publicado la novela EI Viaje (Film de Treinta Minutos). Fue finalista en la Bienal de Novela Premio Copé 2011, con Me He Puesto el Traje Aquel. En 2016 publicó Huaquero (Una Historia sobre la Historia), la cual junto con la anterior conforman su Díptico del Pasado. Contacto: cavagnaroff@gmail.com
} 
A fines de los años 70 José Casals expuso sus fotografías de Puruchuco'. El catálogo incluía un largo ensayo de Jorge Eduardo Eielson. Para la ocasión el artista-poeta-chamán, que había rescatado y se había apropiado del legado prehispánico para recrearlo desde su exilio italiano, hacía lo propio con el paisaje costeño, que ahora alberga un complejo arqueológico restaurado en 1961 por Felipe Jiménez Borja. No obstante, antes de continuar, es importante entender la situación de Puruchuco como referente artístico.

Algunos años antes, entre 1960 y 1961, Reynaldo Luza también había fotografiado el apenas restaurado Puruchuco, con lo que dejó de pertenecer a esa categoría con la cual es frecuente referirse a las estructuras prehispánicas, ruinas, para luego convertirse en el lugar de exploración del artista fotógrafo y el poeta visionario. Sin embargo, como escribe Eielson (2017) en su ensayo sobre Puruchuco, existe algo que diferencia el uso del término:

[L]a ruina — la venerable edad, la estirpe abatida — rezuma de otras verdades secretas que la oficialidad de la historia no consigna. Hay en ella como una película de tiempo acumulado, costra de antiquísimas heridas [...], puesto que la tradición artesanal de los antiguos peruanos no morirá nunca, a pesar de las feroces leyes consumísticas y la nivelación de las costumbres.

Eielson revalora la ruina por su carácter de depósito temporal de otras verdades secretas, que opone a la oficialidad de la historia. Establece así una serie de dualidades que mantendrá a lo largo de sus reflexiones ensayísticas y sus obras, tanto escritas como plásticas.

\section{¿Deshabitado o habitado?}

La serie de fotografías de Puruchuco de José Casals se presenta como la confirmación de una presencia que a nivel del discurso se muestra frente a la desnudez e inhabitabilidad del paisaje. Ese lugar, ese repositorio de estructuras y vestigios, revelados u ocultos, es un modo en que el pensamiento de Eielson sobre el patrimonio y la estética de ese patrimonio podrá plasmarse en un ensayo sobre un complejo arquitectónico², sobre la historia y el tiempo, entre trasladarse en él teniendo como punto de partida la presencia de ese patrimonio para poder interpretarlo y estar a su altura.

Puruchuco no es precisamente el paisaje infinito de la costa (entendido como paisaje desolado); es más bien la estructura de una presencia prehispánica en un paisaje que se muestra al pie de un cerro. Un paisaje que, a la luz de un artículo de Mirko Lauer (2007), puede afirmarse era esquivo en la historia de la pintura decimonónica en el Perú. Era de esperar y creer que Eielson estaba a la búsqueda de ese paisaje, plasmado en sus cuadros matéricos de los años 60, que a la luz de su creatividad comunican (incluso hoy y quizá con mayor fuerza que antes) que necesitamos conquistar un espacio y un paisaje que sea primero interior:

En el Perú, el paisaje tiene problemas para manifestarse incluso ancilarmente. No solo por la emigración masiva de los pintores, sino principalmente por un desinterés histórico por las

\footnotetext{
1. Para esta parte del libro haremos uso de diversos artículos de Jorge Eduardo Eielson, no solamente el de Puruchuco, el cual se encuentra en versión online en http://www.vallejoandcompany.com/puruchuco-por-jorge-eduardo-eielson/ y cito desde aquí en su versión online (2017), sino también "Elogio Triste del Tíber", "Correspondencia Interplanetaria", "Situación del Arte y la Pintura en la Década de los 80", "El Paisaje Infinito de la Costa del Perú", "La Religión y el Arte Chavín”, "Luz y Transparencia en los Tejidos del Antiguo Perú”, los cuales se encuentran en Ceremonia Comentada. Textos sobre Arte, Estética y Cultura (1946 - 2005). Además hemos citado partes de las novelas El Cuerpo de Giulia-no y Primera Muerte de María, la primera de ellas incluida en Arte Poética del autor. Cabe añadir que el ensayo sobre Puruchuco se publicó en 1980 por Ed. Organización de Promociones Culturales con el título Puruchuco. Fotos de José Casals con Texto de Jorge Eduardo Eielson.

2. Es la misma idea del vestigio que se encuentra detrás del uso de ropas (las mismas que luego se anudarán) pegadas en cuadros o "formando figuras", vestigios de la presencia anterior del hombre, por poner un ejemplo de la obra plástica de Eielson.
} 
vastas zonas "atrasadas" del país consideradas todavía en el inconsciente nacional de alguna manera el lastre de cualquier proyecto (...) No pensaban así los viajeros extranjeros que produjeron la casi totalidad de la pintura documental del siglo pasado [XIX]; no solo eran artistas: de cualquier oficio, de un comerciante, de un marino, de un minero podría surgir un pintor o un dibujante ávido de captar naturaleza y sociedad, y sus relaciones. La situación se presta a las comparaciones: no nos vimos, nos vieron; no nos descubrimos, nos descubrieron ${ }^{3}$. (p. 292)

A propósito, Casals era chileno.

Es posible emparentar esa inhabitabilidad del paisaje con la que Fernando de Szyszlo expresa en una entrevista collage, una visión quizá ya desaparecida acerca de la desolación desértica que se está exhumando aquí. Szyszlo se refiere a ella como si se tratara de un "paisaje lunar", lo cual nos acerca al planeta deshabitado que Eielson creía recordar desde su exilio, "un planeta salvaje", "una simple esfera muerta como la luna, desierta, mineral, cristalina", "una nebulosa de algodón y caña de azúcar, de petróleo y tungsteno", un espacio más bien habitado por los recuerdos de las personas que amó (2010, p. 50).

Se trata de dos categorías que refuerzan el modo en que los artistas de la época veían el desierto que rodeaba el otro desierto que era Lima. En su testimonio, Szyszlo describe lo siguiente:

Un tiempo más tarde se produce un cambio muy importante en mi pintura. Mi estudio quedaba entonces en Villa, y durante 6 años para llegar a él tuve que avanzar por el desierto hacia la playa. Y esta sensación tan limeña del mundo como un paisaje lunar ${ }^{4}$ seguramente se me fue metiendo, y es así, pienso, que se produce un cambio fundamental: mis formas, que antes se encontraban ubicadas delante de un telón de fondo pasivo que no trabajaban, comienzan a participar activamente en el cuadro. Y es entonces que aparece una forma completamente vacía, que simplemente representa la sensación de fondo en un paisaje lunar. (Lauer, 1975, pp. 52-53)

Exhumación, porque muy poco de la desolación que rodeaba a Lima en esos años se puede imaginar hoy. Es decir, exhumar lo inhabitado del desierto limeño fuera de sus extramuros coloniales. En la memoria de Szyszlo, Lima estaba rodeada de un desierto, un paisaje inhabitado. Los años y las migraciones anteriores a fines de los 70 (época del ensayo de Eielson) e incluso las posteriores, que no han cesado, transforman ese paisaje: ahora habitado como consecuencia, por un lado, de la migración interna de esos años (informal) y, por el otro, de una urbanización (formal) de los límites de la capital. Y, al mismo tiempo, marca el antecedente y el origen contemporáneo que separa a Lima del resto del Perú. Lima, una capital emplazada en un desierto lunar como si se tratara de un planeta deshabitado.

Es 1979.

Muchas cosas han de ocurrir.

\section{Nudo: Huella, enigma, lenguaje}

Apenas un par de años después, en 1981, aparecerá en la revista Hueso Húmero un adelanto de lo que sería la novela Primera Muerte de María, publicada en su totalidad recién en 1988 por el Fondo de Cultura Económica de México. Bajo el título"11 de setiembre de $1980^{\prime \prime}$, en dicho adelanto Eielson argumenta lo que considero no un

\footnotetext{
3. Énfasis del autor.

4. Énfasis del autor.

5. Cito la edición de la novela de 2014: "Eielson publica en 1981 un fragmento de la novela, tomado de la entrada '11 de setiembre de 1980', que envía a manera de respuesta a la entrevista '¿Por qué no vivo en el Perú?', que aparece en el número 8 de la revista Hueso Húmero" (Eielson, 2014, s/n).
} 
nudo que comunica, sino ese otro paradigma que busca vincularse a través de los tiempos con la gran base prehispánica, y se coloca dentro del espacio infinito como un chamán exorcizador de esa enorme conciencia enterrada, que trata de alcanzar ese otro origen. Aquí el nudo se muestra como el enorme catalizador de una inestable y dolorosa contradicción:

A las insípidas, muchas veces cómicas, veleidades de la superficie, a la inconsistente ciudad colonial, opongo la fulgurante majestad subterránea: templos, reinos y ciudades sepultadas bajo una estéril cáscara de polvo, bajo el obtuso oropel hispano, hoy convertido en cemento, harina de pescado, frustración, patética soberbia. (Eielson, 2014, p. 87)

Imagino que por esta suerte de sincera catarsis esta novela fue publicada en México en 1988, y recién en 2014 pudo ver la luz pública en el Perú. Estamos a caballo entre 1980 y 1981. El chamán está exorcizando su propia creación, tanteando (como ya lo había hecho antes) el enigma subterráneo bajo ese inmenso lienzo tendido sobre la faz dorada de nuestros antepasados.

Alcanza entonces este breve fragmento para advertir que no es esta una correcta forma de acercase al pasado. ¿Es la conciencia del pasado subterráneo una forma de invocar oscuras fuerzas [que se intuyen] vivas en el complicado nudo de nuestra historia? Y lo que es aún más estremecedor... ¿es nuestra historia un complicado nudo?

Esto, por otro lado, lo podría suscribir la invisible forma que gobierna la cultura en el Perú. No es correcto (pensaría este ente invisible -llámese cultura dominante o culturas dominantes-) "propiciar la búsqueda de la raíz contradictoria y conflictiva de la peruanidad, sino (...) buscar los factores de integración del sistema cultural peruano, las 'raíces' capaces de atravesar la línea de clase y proporcionar un común denominador" (Lauer, 2007, p. 182). Nuevamente, en Primera Muerte de María se encuentra lo siguiente:

La arena lo atraía con fuerza, como si debajo de ella se escondiera un enorme imán. Tal vez porque ahí yacían los huesos de sus antepasados. Y no solo sus huesos, sino todos sus enseres, vasijas, vestidos, utensilios, armas, joyas, esteras. Una vez tropezó con una suerte de camisa de tejido finísimo, con largos flecos y una fila de pelícanos bordados en la parte inferior. Había sido, sin duda, el atuendo de un pescador como él. Le sacudió el polvo y la arena y se la probó de inmediato. Le quedaba tan bien que parecía hecha a su medida. (Eielson, 2014, p. 57)

El acercamiento mágico a la muerte y sus remanentes, que son a su vez vestigios de una antigua presencia del pasado, ¿se convierten así en una forma de invocación? Entonces, ¿imaginar e invocar el pasado subterráneo subvierte a modo de magia la propia realidad? Esta misma inquietud es asumida conscientemente por Juan Javier Salazar ${ }^{6}$, quien por esos mismos años con su serigrafía Algo Va a Pasar (Inmediatamente) sugiere esa calidad mágica del arte. Cuando se juntan historia y arte (magia), ¿aparecen estas fuerzas?

En conversación de 1985, Juan José Salazar revela a Gustavo Buntinx lo siguiente:

Como la presencia perturbadora de momias repartidas en el marco de la estampa, donde comparten un connotativo espacio con la figura del propio artista. O la ominosa frase "algo va' pasar" repetida hasta constituir la espesa trama de amarillos en el fondo del grabado. En

6. Para visualizar al artista y su obra Algo Va a Pasar (Inmediatamente), se puede reproducir su testimonio en el siguiente enlace: https://www.youtube.com/watch?v=N3PCE62kHDo. Se debe tomar en consideración además que la obra del artista plástico estuvo en el Pabellón Peruano en la 57 Bienal de Arte de Venecia (2017), a poco menos de un año de su muerte, muestra que en junio del mismo año ha generado en Lima una serie de críticas en relación a la forma en que ha sido presentada la obra del autor, como "la cuestionable manipulación de una obra de Salazar que se vio reproducida y transformada en un dudoso elemento museográfico" (http://larepublica.pe/cultural/888492-artistas-se-pronuncian-sobre-manipulacion-en-obra-de-juan-javier-salazar). 
azul cerúleo irrumpe el término "inmediatamente", caligrafiado sucesivas veces. Tales palabras evidencian una expectativa ideológica al mismo tiempo que componen el sentido plástico de la obra. Pero su reiteración obsesiva sugiere además un ritual, un acto de magia. Salazar ha reconocido que en la confección del grabado no pretendió tan sólo comentar una realidad, sino influir directamente sobre ella con una obra que -sin dejar de ser arte-fuera talismán y panfleto a la vez. Engarzaba así el discurso político moderno a una invocación de oscuras fuerzas que intuía vivas en el complicado nudo de nuestra historia ${ }^{7}$. $(2005$, p. 88)

Volviendo a Eielson, a nivel subterráneo es claro que en la ficción el chamán cree encontrar esta figura de concordancia entre el pasado y su presente bajo el paisaje. Del mismo modo, como a nivel ensayístico, Puruchuco es el vestigio revelado. No una ciudad subterránea: más bien el enigma está sobre la tierra, a la vista de los pobladores de la ciudad. Puruchuco se manifiesta como hallazgo del universo, del cosmos que aparece junto a la montaña para revelar a quien quiera estudiarla la revelación de su signo, el vestigio, el enigma.

Desatar el complicado nudo y alcanzar nuestra dorada faz.

Este nudo se desata y, por su mágica concordancia, va en busca de otro origen. Eielson (2017) en Puruchuco expresa:

Si consideráramos estos restos como los signos materiales de un lenguaje desconocido, nuestra percepción y conocimiento de las culturas prehispánicas quizás se iluminarían con una luz diferente. Si aceptamos la genial intuición borgiana del lenguaje como doble del universo, podemos también -haciendo la operación inversa- considerar los petrificados reinos antiguos como dobles del lenguaje. Si tenemos en cuenta, además, que tan brillantes culturas aparecen, florecen y mueren sin dejar trazas de una lengua escrita, se hace plausible una teoría que clasifique y ordene los restos antiguos con criterio semiológico. De otra manera, tales restos seguirán escapando a nuestra comprensión, a nuestros inmóviles patrones mentales (...) La mayor tarea, claro está, sería el ordenamiento de los múltiples datos, subterráneos o no, surgidos directamente de la experiencia, hasta conformar ese alfabeto de base, ese código primordial que nos permita recuperar una sintaxis y una semántica perdidas.

Encuentro pues una tensión entre esa secreta civilización del pasado y aquella heredera de esa (des)memoria, subterránea o no, oscura (por desconocida), en crisálida, cuya herencia debe rescatarse para encarar el futuro. De este modo, cabe preguntarse ¿cómo enfrentarse al pasado?, ¿cómo asimilarlo dentro de la propia subjetividad?

Una reconstrucción arqueológica, por un lado, y una síntesis literaria, por otra, que ordene su debido aquilatamiento.

Los restos arqueológicos como Puruchuco son huellas que quien las ve no debe acercarse de forma distante frente a algo extraño que viene del pasado, el del presente, sino que, en plenos cambios que se empezarán a gestar en la década del 80, es "colocándose inmediatamente al nivel de las mismas" que se puede encontrar la perspectiva necesaria. Por esos mismos años Eielson escribirá un ensayo sobre Chavín. Ante la matriz cultural peruana, la perspectiva cambia. Estupor y reverencial temor son dos de las formas en que el chamán se aproxima al origen andino de nuestra cultura. Una suerte de síntesis abstracta cifra un lenguaje y una divinidad "que desafía a lo humano". Una abstracción que esconde un lenguaje "cabal y cerrado". Sobre la propia estructura ceremonial regida por una casta sacerdotal, expresa "el laberinto lítico es, pues, un lenguaje completo, cuyo código de lectura va desde la posición de las estrellas (Orión gobierna las cosechas de Chavín, según Lumbreras) hasta las supuestas exigencias sacrificiales del dios representado" (Eielson, 2004, p. 557).

7. Énfasis del artículo original. 


\section{Iconología, historia y poesía}

Cuántas veces, visitando algún museo, europeo o local, alguna colección pública o privada, o simplemente un anticuario, había constatado con euforia que mis propias apreciaciones sobre la autenticidad, época, cultura, autor o nivel cualitativo y estético de ciertas piezas coincidían -e incluso, a veces, iban más allá- de las de los expertos más o menos oficiales. La euforia -claro está- no era debida a un banal orgullo, sino a la profunda alegría que me causaba el reconocimiento inmediato de una entidad histórica y artística. La intuición poética ${ }^{8}$, ciertamente, me ayudaba mucho en ella, y no pretendo negarlo.

Para aproximarse a lo expresado por Eielson en su ensayo Puruchuco, ¿debería la metodología también ser la intuición poética? Esto trae a colación lo expresado por César Moro, otro poeta, artista plástico y también chamán surrealista, sobre cómo debemos acercarnos al pasado prehispánico. La propia mirada de Moro se coloca al nivel de ese pasado (dentro de él, y le es posible moverse allí), tal y como Eielson expresa en Puruchuco. Para Moro (2002), existe un acercamiento

...de orden emocional, irracional. Repentinamente trato de alcanzar -sucede que vivo ese mundo, aunque sea milenario. No experimento ninguna dificultad de moverme en él, por más remoto que se encuentre en el tiempo, también ignorado, como el mundo pre colombino. Huacos funerarios del Perú, petroglifos de Canta, que cubren literalmente los cerros, cuyo origen y cuya época se desconocen, me son próximos como el Ojo Real, mucho más próximos que la sórdida expresión del mundo que me rodea.

Es evidente que el placer estético no progresa con el conocimiento intelectual, con frecuencia hipotético en estas materias. Ese placer es distinto, nos ayuda a situarnos mejor en el mundo, en nuestro mundo. (p. 461)

Moro hace una excelente distinción entre ese "placer" estético que Eielson denomina intuición, pero además, muy consciente del carácter evolutivo de la ciencia (bajo la cual se desarrolla la arqueología), muestra esa mutabilidad, ese escanseo de saber que deja atrás las certezas para luego modificarse.

Por ello, si se trata de un enigma estructural cuya raíz, en palabras de Eielson, es sintáctica, este vestigio debería ser leído a través del hermano lenguaje, que a su vez es hermano del universo. Es posible llegar a encontrar las piezas de ese alfabeto que cada parte del patrimonio prehispánico constituye, y a través de él acercarse al universo. Alcanzar una concordancia entre la actividad del hombre y la actividad de su entorno, y a través de ella con el universo entero.

Eielson (2017) llega a ese misterio de manera intuitiva: observando ese planeta (o paisaje) deshabitado se topa con esa estructura que parece reproducir un lenguaje del cual el autor ha ido haciéndose consciente durante años. La intuición poética ha revelado esa concordancia con lo universal, en el sentido cósmico, tal y como lo escribe en Puruchuco:

Es en las raíces más arcaicas de estas culturas, en sus geniales elaboraciones matemáticas a partir de ciertos signos estelares, largamente observados y domesticados, hasta formar parte de su vida cotidiana; es en calidad de una visión cósmica diversa -que el racionalismo

8. Énfasis del autor 
occidental no logra aún discernir- en donde reposa un ordenamiento tan preciso y esencial como el de Puruchuco.

Nuevamente estamos frente a esas geniales elaboraciones matemáticas dispuestas frente al racionalismo occidental. Una frente a la otra. ¿Cómo entender el pensamiento estelar en la disposición del espacio por un lado, y el uso de íconos y objetos que se creían decorativos, o simplemente estéticos? ¿Cuál ha sido hasta aquí el desarrollo de la iconología por un lado y la estructura dentro del espacio sagrado, piezas fundamentales ambas de ese lenguaje hermano del universo?

En relación a este mismo aspecto, Eielson (2004) también lleva la mirada a Chavín, en tanto una religión liderada por una casta sacerdotal de la que quizá los maestros artistas formaban parte, quienes llevaban encumbradas abstracciones con un estilo "impuesto por la dureza de la piedra, por el punzón y la maza" [el cual] "se perpetúa y se desarrolla de mil maneras, todas las cuales encierran fragmentos, residuos de la divinidad lítica. Una insondable capacidad de abstracción y de síntesis asiste a esos artistas" (p. 558). Eielson (2004), allí y a lo largo del ensayo, evidencia esa forma de denominarlos. En esto es polémico: tratando de llevarlos fuera de su ámbito total, los hace contemporáneos a la idea de artista. Por un lado, quien alcanza un entendimiento natural y metonímico de su sistema de creencias expresadas en su propio mundo difícilmente podrá concebir un sentir metafórico de la realidad, y con ello artístico: "Esto confirma un punto de vista sostenido por el autor desde hace mucho tiempo, respecto a toda la actividad creadora: es decir, que los artistas fuertemente imbuidos de sentimiento místico, tienden a la abstracción" (p. 559).

De esta forma, estos artistas místicos (según la categoría eielsoniana), estos chamanes mágicos de las piedras de adoración y sacrificio elaboraron y materializaron para sus desconocidos dioses, dentro o fuera de Chavín de Huantar, en el Castillo o Templo Tardío, "complejo arquitectónico que conformaba, sin lugar a dudas, un gran centro ceremonial y ritual existente hace ya unos cuatro mil años", el enigmático Lanzón, el Obelisco Tello o la tardía Estela Raimondi, que "eran igualmente otras manifestaciones de la misma religión, [una humanidad] que parece no haber existido sino para un solo fin: la adoración de sus dioses y, a través de estos, a la elaboración de una cosmogonía y un arte violentamente sacudido por el sentimiento místico. Sólo así podremos acercarnos algo más al centro del fenómeno Chavín, aunque una cabal comprensión del mismo nos será siempre negada, debido a nuestras muy diversas estructuras culturales y mentales" (p. 660).

Estética o religión.

La estética de una religión.

La religión de una estética.

Esa distancia que Eielson devela permite aquí esbozar el aporte del historiador de arte Erwin Panofsky como uno de los antecedentes del análisis iconológico, cuya influencia en la interpretación iconológica le sirve a Anne Marie Hocquenghem para trazar una magistral interpretación del caso Mochica (y por extensión del mundo andino). Según este análisis, existe una noción panandina de los mitos y los ritos. De esta enorme cosmovisión, las actividades de las comunidades andinas y costeñas (como Puruchuco) han estado ligadas al ciclo agrícola y cada una de ellas se ha dirigido a la consolidación de dicha estructura conceptual, para así organizar mitos y ritos, incluidos en ello la naturaleza animada, el orden cósmico y social, además del mundo paralelo de vivos y muertos. En palabras de Krzysztof Makowski:

Solo las artes figurativas permiten entrever algo de lo que estaba pasando en los llamados "periodos oscuros", o de estudiar las creencias y costumbres de las clases medias y bajas, 
seguir los movimientos religiosos, así como entender las culturas de los pueblos sin escritura asentados en las periferias. (citado en Hocquenghem, 1987, p. 11)

Panofsky plantea tres enfoques con los cuales es posible acercarse a este tipo de íconos, excelentemente sintetizados por Hocquenghem. Es filológica aquella visión que se origina en la arquitectura clásica de fines del siglo XVII, cuyo objetivo era encontrar nexos entre el legado literario y lo material. Se desprende de ello que no había una crítica de las fuentes; en su lugar existía una deficiente cronología con un mapa cultural borroso y falto de integración con las ramas humanísticas. Es este, por ejemplo, el caso de Hienrich Schliemann, quien en los albores de la arqueología, solo insuflado por su pasión por los clásicos homéricos, decidió comprobar que la Troya de la llíada había efectivamente existido, hazaña que el poeta Javier Sologuren poetizaría en Recinto (1967) como metáfora de la génesis de la poesía y el acto creador.

Un arte poética arqueológica y huaquera.

Por otro lado, el enfoque tipológico organiza largas series de símbolos a través de los siglos, demostrando así de forma global que los motivos sobreviven milenios a la cultura que las creó. Finalmente, en el enfoque iconológico, la imagen se analiza en relación con los diferentes contextos en los que se encontraba en el pasado; se lee su estructura interna comparándola con otras del mismo contexto. Según Krzysztof Makowski en Hocquenghem (1987), "Una vez adquirida la capacidad de aislar los motivos -las 'palabras'- dentro de la representación, se puede pasar a la etapa siguiente y tratar de entender el principio de la composición, -la 'sintaxis'- de las imágenes" (p. 14).

Motivos como nudos.

Sintaxis como redes.

Arquitectura monumental como nudo: red de templos prehispánicos hermana del lenguaje y del universo. La intuición poética de Eielson (la estética de Moro) se presenta así como un primer paso para acercarse a la recolección de datos. Una primera etapa del entendimiento. Nudos que al tiempo de tejer urden una trama con otros nudos, los cuales podrán advertir un orden, un lenguaje, como si cada ¿signo?, ¿símbolo?, ¿motivo?, fuera la letra de un alfabeto. Alcanzar de ese modo el significado final, develando la metáfora y alcanzando en su lugar la metonimia, podrá ser la solución del enigma urdido al pie de la montaña.

Hocquenghem (1987, p. 194) cita a Roman Jakobson, quien plantea la diferencia entre metáfora y metonimia para explicar los problemas en la actividad lingüística, que le sirven a la estudiosa para trazar una diferencia entre el modo en que concebimos las imágenes mochicas y cómo lo hacían en su tiempo quienes estaban bajo el gobierno de dichos símbolos. Hocquenghem establece una diferencia entre lo que se entiende por metáfora y metonimia, colocando a esta última como la forma en que los peruanos del pasado entendían la realidad. Los peruanos contemporáneos podríamos advertir una figura poética, una metáfora en esos nudos. Podríamos pensar que esos motivos son simples cumbres estéticas... Según la diferencia en la que se basa Hocquenghem, que toma como base la dualidad establecida por Roman Jakobson, los mochicas veían y plasmaban la realidad que los circundaba. No se trataba de una imaginería analógica ni de semejanza; era más bien una relación de contigüidad, como si la realidad que describieran fuera en todo caso una realidad que estuviera al alcance de la mano, contigua a ella. Al respecto, Rosella Pugliese (2010) sostiene lo siguiente:

Nel secondo momento, [il momento metonímico] il parlante costruisce il messaggio legando i diversi elementi per contiguità (la combinazione è operata sulla base della contiguità) ed essa rappresenta la "direttrice metonimica". Jakobson considera la metonimia come una sostituzio- 
ne di un termine con un altro che ha con il primo un rapporto di contiguità, mentre ritiene che la metafora si basi su un rapporto analogico, di somiglianza? .

¿Debemos contentarnos entonces con metáforas de la realidad o buscar la realidad misma de estas imágenes? La intuición poética es un primer escalón hacia el cabal entendimiento. No una deformación ni tamiz, sino su total entendimiento. Más allá de una aproximación primera en la que la intuición poética ha sido la que nos ha puesto al mismo nivel del vestigio, frente a él (tal como en el programa Eielson), es posible dar el siguiente paso hacia un enfoque iconológico (movernos dentro de él, tal como en el programa de Moro). Interpretar en principio su significado, develar, atravesar el nudo para empezar a urdir nuestro verdadero vínculo subterráneo que no esté divorciado de la realidad, que no sea meta; sino que sea tangible y real:

Los términos "metáfora" "y "metonimia" han recibido en el pasado una carga ética, ideológica, que no debe ser ignorada aquí. [...] Jakobson mismo asoció poesía con metáfora, prosa con metonimia [...] La teoría de Jakobson ha llevado a los críticos a considerar a la metáfora por encima de la metonimia y considerar a la primera como el proceso más creativo del intelecto humano. En tal contexto parecería que privamos a los mochicas de una facultad mental "superior" lo que hacemos es paradójico, ya que los mochicas solo producían un mundo integrado de ancestros y seres vivos estableciendo relaciones metonímicas. Lo que es "poético" para nosotros era "real" para ellos. Nuestra superioridad de establecer relaciones metafóricas se convierte en inferior a su habilidad para crear e integrar un mundo en el cual la visión del mundo y el paisaje no están divorciados. Sus presentaciones eran más realistas que románticas. Está por demás decir que tenían necesidad de alegorías y, de hecho, no hubieran podido acomodarlos ya que no tenían un mundo de ideas divorciados de la realidad. (Hocquenghem, 1987, pp. 194-195)

Esta es una de mis partes preferidas del libro nuclear de Hocquenghem. Habría que complementar aquí lo expresado por Eielson (2004) en relación a Chavín, que se muestra mucho más enigmática que Puruchuco al respecto pues

...tales representaciones se hallan siempre encuadradas dentro de un marco que trasciende el mero realismo. Para los artistas Chavín la fuerza del mito religioso está presente hasta en la misma naturaleza (...) La vastedad de su código de lectura reposa sobre pocos, reconocibles caracteres formales, como la repetición, simetría, la sustitución (Rowe) (...) El lenguaje de los artistas se ha destilado hasta lo inverosímil, de manera que los signos exteriores de lo sagrado aparecen reducidos a lo esencial, a una mera caligrafía, cuando no a pocas líneas curvas, puntos, círculos, triángulos, que fueron garras, lomos, ojos, manchas, plumas, colmillos. Abstracción que es un proceso de síntesis (...) imagen cifrada desde el comienzo del alfabeto. (pp. 562-563)

Hago aquí una necesaria diferencia entre el modo en que Eielson describe Puruchuco y el modo en que lo hace con Chavín. Se trata de la matriz de la cultura peruana, tal y como la pensaba Julio C. Tello. Y, sin embargo, existe una diferencia primordial: Chavín aparece a los ojos de Eielson como un sistema congelado en el origen, puro en su mostración, mientras que Puruchuco posee las huellas de un devenir histórico mucho más obvio. Sin embargo, los signos están ahí en ambas edificaciones. ¿Qué implica para la cabal interpretación que uno de esos enigmas vestigio, ese patrimonio, se haya mantenido impoluto en su presencia milenaria, y el otro haya tenido diversas funciones a lo largo de la historia? ¿Eso cambia su interpretación, o el origen siempre es inmarcesible?

9. La metonimia in Kyra Kyralina di Panait Istrati de Rossella Pugliese se puede ver en el siguiente enlace: http://www.tesionline.it/consult/brano.jsp?id=11444 


\section{Legislación: La Religión y el Arte Chavín (1981)}

El tráfico de antigüedades y tesoros nacionales, patrimonio cultural material y toda la gama de objetos arqueológicos, es un mundo que está atravesado por miríadas de objetos individuales y leyes nacionales que colisionan con su débil ejecución o ignorancia $y$, por otro lado, por una red de influencias que como problema esencial tiene una raíz internacional, global, cuya solución se "avizora", del mismo modo, universal. The Plundered Past de Karl E. Meyer (1973) es un libro importante que retrata un momento esencial en la historia legal de este problema, tan antiguo como la propia existencia del hombre.

En 1970 tuvo lugar una reunión global auspiciada por la Organización de las Naciones Unidas para la Educación, la Ciencia y la Cultura (UNESCO), que tenía como objetivo implementar el primer conjunto de leyes globales. Esta fue impulsada por los países que "producen" el arte antiguo, y hasta entrado el siglo XXI fue suscrita por algunos países que "consumen" dicho arte o patrimonio. El libro de Meyer, que registra este acontecimiento, se publica tres años después de este hecho, y plantea un claro paralelo entre el pasado del coleccionismo (Elgin vs. Byron; coleccionismo vs. nacionalismo), y esta nueva herramienta legal y lo que estaba ocurriendo en esos momentos ${ }^{10}$.

París fue la ciudad en la que se consolidó el grupo de especialistas que redactaron la más importante ley mundial sobre patrimonio: Convention on the Means of Prohibiting and Preventing the Illicit Import, Export and Transfer of Ownership of Cultural Property (1970). Como se puede barruntar, la ley no detuvo el fenómeno; más bien tuvo un movimiento azaroso.

La misma sensación de confusión entre los niveles en los que se desarrolla el problema, en esa tensión entre universalidad y localidad dentro de un museo imaginario mundial repleto de objetos de diversas procedencias, cuya existencia es ignorada (o conocida) por los estudiosos de cada una de las diversas regiones del planeta, se respira una vez esbozado el conocimiento del problema. Si se piensa en los objetos, entonces se debe pensar en su propia historia, una historia que se divide entre su existencia subterránea y la que cuenta luego de extraída de la tierra, entre su destino suspendido entre las manos de arqueólogos o depredadores, entre museos o almacenes de ventas, entre casas de subasta y gabinetes de coleccionistas, entre universidades e institutos de cultura. Entonces es su propia historia la que se cuenta, pero también existe el cuerpo legal que la engloba. De forma contigua, existen diversos cuerpos de leyes nacionales, locales, federales, universales, diversos aspectos que atraviesan la "vida" del objeto: historia, procedencia, angurria y redes mundiales de dispersión que se de-

10. Grosso modo: Lord Elgin deseaba preservar las reliquias griegas del Erechtheum, Ilevándolas a su propiedad en Bromhall, Escocia, y encender con su manifestación un deseo estético por la belleza, fecundar la imaginación de los artistas. Pero lo que debería ser primero una medida para hacer fakes bien intencionados, o simples copias para reproducir en Inglaterra, entre artistas y arquitectos, un fundacional deseo de recreación de la belleza clásica, acabó en el traslado de esos vestigios como propiedad particular de Lord Elgin, con el pretexto original de salvar esas piezas de la dejadez griega y de los peligros de su guerra de independencia. Luego de una serie de vicisitudes, estas fueron vendidas al British Museum. Este es un modo de entender el coleccionismo. Por otro lado, el punto de vista de Byron anticipa más que una razonada motivación, una explosión de emociones, aquella que, desde el romanticismo hasta el nacionalismo germinado en cualquier parte del mundo, se opone a la explotación de reliquias del pasado de parte de europeos y americanos. Esta visión nacionalista de Byron despierta por primera vez (en el mundo moderno) aquello que se piensa como el acto de privar a un país de su herencia histórica. En consecuencia, son estas las tres formas en que se podría resumir las actitudes frente al pasado: el punto de vista del coleccionista, Lord Elgin; el del curador o admirador estético; y el nacionalismo de Byron, el cual defiende el patrimonio nacional. 
tienen, ocultan, segmentan, reaparecen el bien material, a través de los años, décadas, siglos. Existe pues un desbalance en la existencia del objeto.

Esto da la idea de un inconmensurable e infinito espacio, donde lo verdadero y lo falso cohabita con las reales y falsas historias, donde lo prehistórico, lo contemporáneo, lo industrial tienen una procedencia indistinta: una vasta pirámide con huaqueros, coleccionistas, pasantes de arte, abogados, asesinos y toda laya de personajes. Es decir, un problema cuya solución pareciera albergarse en el lugar más alto de una gran torre, babélica y utópica.

Esa imagen de inconmensurabilidad es descrita por Eielson en su novela de 1971, El Cuerpo de Giulia-no, como si ese conjunto de objetos estuviera finitamente reunido en un pedazo de París, pero de un modo caótico, donde lo precioso está en una posición de contigüidad con lo falso, lo feo, lo cotidiano. Esta misma idea de emplazamiento temporal y material, de la ocupación del espacio por diversas capas de tiempo, expresadas a través de la materia que las ocupa, pero que no es el espacio natural en el que se encuentran de manera azarosa los objetos, sino más bien un (des)ordenamiento de cosas, apiladas en contigüidad, dispersadas en su contexto original, por la estructura comercial de un mercadillo en aux Puces (París), centro en el cual los personajes de la novela también pasean su propia confusión identitaria y temporal.

Aux Puces se transforma así en un lugar lleno de objetos de todo tipo: reliquias históricas, objetos triviales y fakes. De forma paralela, sin embargo, en ese caos, la búsqueda utópica es un ideal a perseguir, una búsqueda de objetos que nunca se encontrarán: el Gran Traje de Seda o la antigua Venus Anadyomene. ¿Cuál es la versión que buscan? ¿La original o la desaparecida de Roma?

...entre corredores de lámparas Tiffany. Consolas Imperio. Muñecas degolladas. Cerraduras. Máscaras Dogón. Baterías oxidadas. Anteojos. Collares. Espejos. Estampas barrocas. Japonesas. Belle époque. Medias y zapatos usados. Sarcófagos egipcios. Falsos Puvis de Chavannes. Falsos Toulouse Lautrec. Discos de Caruso. Dentaduras postizas. Falsos santos bizantinos. Medias y zapatos usados. Crinolinas. Veneno para las ratas. Porcelanas Meissen. Soldados de plomo. Colchones pestíferos. Televisores rotos. Veneno para las ratas. Falsos bronces etrus cos. Falsos cuadros de Renoir... (Eielson, 2004, pp. 406-407)

En esta suerte de reflejo caótico del mercader y lo falso, siempre en búsqueda de lo ideal, en el que todo se mezcla espacial y temporalmente en un caos contemporizador y homogéneo, en el que todo se descontextualiza por el comercio y pierde identidad, es allí, en ese desorden material y temporal, en esa acumulación donde todo puede ser comprado y falseado, es allí donde se encuentra un anticipo de la acumulación de información y comercio de la virtualidad, en la que la confusión impera.

En la base comercial de la pirámide que representa el comercio ilegal de las piezas del arte antiguo, están los huaqueros, sobre quienes Eielson se expresaba en su novela de 1988 (Primera Muerte de María) del siguiente modo:

Pero, sobre todo, se quedó muy impresionado cuando por primera vez pudo observar algunas momias apenas extraídas de un antiguo cementerio. Algunas se hallaban cubiertas de joyas y de riquísimos mantos y otros aderezos multicolores, con máscaras doradas y abanicos de plumas brillantes. Otras envueltas en unas simples mantas color tierra, con toscas máscaras de madera roja y algunos vasos sencillos (...) José las había observado atentamente, casi con veneración (...) lo asaltaban unos deseos incontenibles de abrazarlas y llorar sobre ellas, como se abraza y se llora sobre los hombros de un padre o de una madre. Criaturas que la muerte había vuelto indefensas, hubiera querido insultar, castigar a aquellos que las desenterraban y saqueaban sus pobres huesos, pero se quedó paralizado. Como si en realidad se tratara de 
sus propios huesos... Se hablaba de centenares de huaqueros devorados por la arena y por el viento paracas, que soplaba más fuerte que nunca en esas ocasiones ${ }^{11}$. $\left(2014\right.$, pp. 58-59) ${ }^{12}$

Los escritores y literatos han jugado un papel primordial en evaluar lo que corresponde al ámbito del patrimonio cultural, sobre todo al material. Fuera y dentro de nuestro espacio cultural. Mi intención final no es aquí juzgar las motivaciones y elecciones de un artista como Jorge Eduardo Eielson, pero sí clarificar cuál era el contexto nacional e internacional al momento en que escribió sus artículos y novelas. Una primera aproximación es la que he expuesto hasta aquí: un recuento ensayístico en el que prima el redescubrimiento del lado más importante de la cultura de lo que hoy se denomina Perú por parte de un artista. Cuando Eielson expresa los acercamientos que hasta aquí se han esbozado, que se han contextualizado para un cabal entendimiento de uno de los grandes problemas globales que a su vez encierra una comprensión contextual y no solo artística de las manifestaciones culturales, lo hace dejando en claro cuál es su posición, la cual puede resumirse así:

- La idea de lo inhabitado del paisaje, tal y como se pensaba en relación al paisaje, refuerza un escenario anterior a las migraciones y habla de un pasado decimonónico, del cual primero los extranjeros y luego los artistas como Eielson empezarán a gestar y a apropiarse de él, incluidas las ruinas prehispánicas, justo antes de que un nuevo periodo democrático empiece.

- El siguiente paso en el programa de Eielson fue dejar en claro que existía una oposición entre la tradición hispana y la gran herencia subterránea que por un lado inhabita el paisaje, pero que en lugares como Puruchuco o en Chavín se muestra a la vista, lista para ser interpretada. Es en los años 80 que Eielson intensifica esa interpretación ensayística y novelística, puesto que antes y después continúa esa exploración, dejando en claro el valor mágico del acto artístico y su correlato en la historia, influenciando soterradamente en esta.

11. Según Peter Watson, existe similar depredación y robo de antigüedades en países como Perú, donde existe además un comercio subterráneo de restos humanos antiguos, llámese momias. Queda claro que su actividad es la más importante dentro del esquema que tiene como fomentador a quien se conoce como el middleman (suerte de intermediario) y el collector. Sin embargo, ya en el momento de la publicación de la investigación de Karl E. Meyer, este refería una entrevista a John D. Cooney, curador de arte antiguo en Cleveland Museum, quien manifestaba que el $95 \%$ del material de arte antiguo que estaba en EE.UU. había sido saqueado de su lugar de origen. Existe también el testimonio de un curador de un museo suizo, quien aseguraba que "es de público conocimiento que el $90 \%$ de los certificados de origen que acompañan estas piezas (works of art) son totalmente poco fiables. In this respect, the trade is also unusual: the falsification of papers is a routine business method, as generally accepted by the seller as by the knowledgeable buyer" (Meyer, 1973, p. 124).

12. Según el testimonio de Fernando de Szyszlo, "Sin embargo, hay algo que no olvido: Jorge era un gran coleccionista. Hacia los años 1945 ó 1946, cuando nos interesamos en el arte precolombino peruano, íbamos Javier Sologuren, Jorge y yo al museo de Magdalena, dos o tres veces por semana. Desde allí empezamos a coleccionar cosas precolombinas, y yo compraba pero no con la locura de Jorge. Él tenía una colección preciosa de cosas peruanas; después también se interesó por las esculturas coloniales, de madera colonial. Cuando se fue a Europa se llevó todo eso, y junto con eso fue formando una colección de arte primitivo. La vida dura que llevó por esos años en Europa la fue desapareciendo. Había que vender para sobrevivir. Pero Jorge, apenas le fue mejor, otra vez comenzó a comprar arte precolombino. Él vino dos veces al Perú, en ambas ocasiones estuvo muy interesado en adquirir cosas, porque, además, tenía muy buen gusto y buen 'ojo"' (Libros \& Artes: Carlos Batalla, 2006, pp. 9-10). Al respecto, Rafael Hastings afirma lo siguiente: "En una de sus visitas, en Tacora conocimos a unos huaqueros que nos invitaron a una 'expedición' a Casma. Fuimos con Manongo Mujica. Fue un espectáculo terrible. Vimos a los huaqueros rompiendo cántaros, trabajando sin cuidado y, de repente, escuchamos: 'Acá está, acá está. Entonces, levantaron la tela más linda que he visto en mi vida. Pero un minuto después su belleza y su colorido desaparecieron por acción del oxígeno que la hizo marrón. Por nuestra culpa 'el ala de una mariposa' se apagó para siempre... [A Jorge] no le gustaba el arte peruano contemporáneo. Eso sí, para Jorge, si te gustaba el arte precolombino eras Dios... Le gustaba cocinar y comer muy bien. Disfrutaba recitando poesía romana de Terencio. Íbamos al Louvre, una vez al mes, a ver una escultura, alguna cabeza romana" (Libros \& Artes: Gonzalo Pajares Cruzado, 2006, pp. 25-26). 
- La intuición poética de Eielson se hermana con el placer estético de Moro, quien antes también encontraba valioso y fascinante el pasado prehispánico. Sin embargo, la abstracción o lo estético de los objetos prehispánicos se puede analizar a través de una metodología iconológica, la cual también identifica una realidad mística en la interpretación de Eielson. Lenguaje y cosmos se revelan así a analistas iconológicos y estéticos como una verdad.

Dicho todo, es sin embargo el mismo Eielson quien abraza una posición claramente elginista, es decir, pro-coleccionismo, en una nota a pie de página en su ensayo sobre La Religión y el Arte Chavín (1981):

Un comentario aparte merecen aquellas personas que, sin ser arqueólogos ni estudiosos de arte, se han dedicado de manera tangible y concreta a la salvaguardia de algunas obras de arte que, de otra manera habrían sido dispersadas por la incuria y la ignorancia. En el Perú, que hasta la fecha carece de un Museo Arqueológico digno de su inmenso pasado, esta labor ha sido llevada a cabo por muy pocas personas, y no siempre con suficiente amor y conocimiento. En la mayoría de los casos, desgraciadamente, han intervenido, o intervienen, factores sociales, de prestigio, e incluso comerciales, que nada tienen que hacer con las obras en cuestión. Todos estos condicionamientos exteriores han impedido la formación de conjuntos homogéneos y bien estructurados, con particular atención a su intrínseca belleza plástica. La colección Poli, de Lima, es, en este sentido, una feliz excepción. Ella refleja plenamente la pasión y el rigor con los que tales piezas han sido reunidas. Entre ellas sobresale con fulgor propio un extraordinario grupo de cerámicas Chavín, digno de los mejores museos, e incluso único en el mundo. No en vano su propietario -que a través de una Fundación se propone donar la colección al estado peruano- espera una sede adecuada en donde dicho conjunto pueda ser conservado, mostrado y visitado en condiciones ideales. (Eielson, 2004, p. 565)

Tal establecimiento aún espera su lugar y construcción definitiva. Aunque ya algunas voces se alzan sobre la posibilidad del MUNA y otros se oponen a ella en caso su ubicación sea en Pachacamac. Es claro que la posición de Eielson es a favor de un coleccionismo que salve tal patrimonio de la incuria y la ignorancia. ¿Podría todo esto oponerse y ser contradictorio (como ocurre con otras figuras literarias) en relación a lo expuesto en las secciones anteriores? ¿O es solo una posición curatorial en alianza perpetúa con una posición elginista? ¿Se aleja así Eielson de una postura "popular", tal y como en alguna ocasión se refirió al poeta italiano Pier Paolo Pasolini? En lo personal me parece clara su elección.

El Perú contará con un Museo Arqueológico digno de su inmenso pasado, luego del cerrado enfrentamiento entre las posiciones que a toda ultranza querían el museo en la ubicación prevista y los que con muchos argumentos, aunque alejados de un apoyo popular, pedían una alternativa a su ubicación definitiva en Pachacamac ${ }^{13}$.

En contexto, la década de los 80 se presentaba como un momento crucial. En lo político se inauguraba una nueva Constitución y se volvía a un régimen democrático. Sin embargo, no será hasta 1987 (un año importante que trae a la palestra nuestro pasado milenario con el hallazgo de la tumba real del Señor de Sipán) que algunos cambios en el marco legal sobre la situación del patrimonio coincidirán con una revalorización del legado prehispánico: la Ley 24047, Ley General de Amparo al Patrimonio Cultural de la Nación del 3 de enero de 1987. Según el testimonio de Alberto Martorell, algunos

13. En ese sentido es impresionante que este artículo, antes, durante y después de la decisión final del Estado, encarnado en el Ministerio de Cultura, haya seguido tanto el tema de la existencia, luego la ubicación del Museo y el destino final de la colección Poli, su procedencia y su origen. Finalmente la posición de Eielson fue así refrendada hasta su futuro, que es mi presente, y pronto pasará a ser un pasado que concuerda con una emblemática tradición peruana de considerar el pasado. La forma en que el presente arrasa con todo y la forma concreta con que silencia las voces discordantes, ¿son todas estas elecciones? Con ello di por concluido en mi fuero interno el proceso que me había llevado a revalorar mi propio pasado prehispánico desde el arte verbal, dando un toque a su conclusión. 
consideraron que dicha ley presentaba muchos vacíos y pocas virtudes, que no se convirtieron en políticas. Gran parte de la discusión se dividió entre arqueólogos pro propiedad pública de todos los bienes culturales y coleccionistas pro propiedad privada ${ }^{14}$.

Cuando Eielson escribe el ensayo que muy brevemente hemos citado aquí, centrándonos en su posición frente a un debate que, como hemos visto, es antiguo, existe lo que podríamos llamar un relajamiento de la primavera proteccionista de inicios de 1970, esto visto de forma global. En relación al aparato legal internacional y su relajamiento, Peter Watson y Cecilia Todeschini (2007) expresan que "In the 1980s, dealers in the market countries introduced codes of ethics, and museums revised their acquisitions policies but, very often, it has to be said, these moves were not much more than window dressing" (p. 32).

La implementación de la ley no tuvo la suficiente fuerza en las siguientes dos décadas de parte de marchantes y museos. En la práctica la revisión de los permisos y restricciones eran tan solo window dressing, o sea, fintas, escaparates sin real determinación. El cuerpo de leyes a veces caótico que expresé en la figura que el propio Eielson desarrolla estéticamente en su novela de 1971, que en lugar de proteger puede llegar a ser contraproducente en su función, lo manifiesta Mariana Mould de Pease al comentar el Decreto Supremo 89 (promulgado en los albores de la República) del 2 de abril de 1822 , que permitía que los bienes culturales muebles pudieran circular libremente en el país y mudar de dominio:

...no entendemos que un país no puede vivir esta dicotomía que alienta el coleccionismo descontextualizado de obras de arte precolombinas o barrocas (...) por ello, persiste la moral personalista del coleccionismo, entendida como la costumbre de afirmar que se compran obras de arte carentes de documentación de origen y procedencia para evitar que sean destruidas o enviadas de contrabando al exterior. (2014, p. 85)

Esta última afirmación me recuerda lo que Eielson expresa acerca de la incuria y la ignorancia. Es esta tensión inicial la que se expresa en la ley de 1987. Algunos años después de aquella ley nacional, ya se puede intuir un cambio de actitud a nivel global. Peter Watson y Cecilia Todeschini lo manifiestan en un reforzamiento de la ley universal de la UNESCO (1970):

In the 1990s, UNESCO sought to tighten up the convention, in particular with regard to the level of "due deligence" that dealers, collectors, and museums must use when acquiring cultural property without a fully documented history. This resulted in the so-called UNIDROIT convention, which was adopted by members countries in 1995 and came into force in July 1998. This convention says, in effect, that dealers, collectors, and museums must take active steps, or "due deligence", to satisfy themselves that cultural property without an adequate documented history has not been illegally excavated or smuggled. In other words, the onus is on the "good faith" purchaser to prove his or her good faith. In the United Kingdom, a new law was introduced in 2004 that makes it a criminal offense knowingly trade in illicitly excavated archeological objects. Thus, there was a crucial change in attitude in the 1990s, the fruit of what had gone before. (p. 32)

Apenas se han citado dos importantes leyes nacionales y dos globales como introducción al complejo mundo que aguardaba a Giulia, Giulia-no y Eduardo en un rincón

\footnotetext{
14. El escueto recuento de leyes nacionales que se realiza a modo de herramienta para reflexionar sobre los ensayos de Eielson está basado también en la información proporcionada por Fabricio Valencia. Por otro lado, el coleccionismo en sí no es el problema, sino el tipo específico que implica la adquisición de objetos de dudosa procedencia, saqueados o robados. Sobre este punto, vengo trabajando un comentario acerca de la figura de Anna Maria Luisa de Médici, Elletrice Palatina, quien legó a Firenze, a través del Patto di Famiglia, diversos objetos que por varios años su familia, los Médici, coleccionaron. No los legó directamente a la ciudad, sino que, por intermedio de un punto específico de dicho pacto, estableció la inamovilidad de esas colecciones, aunque la propiedad de las mismas sería de la dinastía entrante, es decir, los Lorena.
} 
de aux Puces, y además hemos podido aquilatar la contradictoria condición de artista (sobre todo esto) y ser humano de Jorge Eduardo, entre su propia intuición poética y una opinión acerca del destino de nuestro patrimonio mueble. De este modo, además, se ha comprobado cómo la legislación sobre el patrimonio ha ido y venido, ha sido estable y cambiante.

Finalmente, Jorge Eduardo Eielson ya había fallecido cuando se organizó una muestra sobre sus trabajos plásticos y aquellos objetos prehispánicos que había coleccionado, planteada por el Centro de Estudios que lleva su nombre en 2013, y a la que se denominó Eielson. Artista e Collezionista. Tessuti Precolombiani e Dipinti Contemporanei, y se inauguró el 6 de mayo del mismo año en el Palazzo Medici Riccardi, Firenze. En la presentación online ${ }^{15}$ de esta exposición se afirma que

....sarà possibile osservare oltre 30 opere tra referti storici di varie civiltà preincaiche (quali Chancay, Paracas, Chimù), provenienti dalla collezione privata d'arte precolombiana di Eielson; saranno esposte in parallelo alle opere dell'artista, che proprio da queste culture ha preso ispirazione per la sua ricerca poetica, quali la "Suite Paracas", tela che rappresenta figure umane stilizzate, "Unku", abito cerimoniale di ispirazione peruviana. Non mancheranno, inoltre, i "Quipu", celebre serie di opere di Eielson ispirate all'antico sistema di comunicazione basato sui nodi, traccia degli antichi 'quipus amerindi' (i nodi della cultura inca) e sintesi del legame tra le sue origini latinoamericane e l'esperienza europea.

Eielson no era solamente un admirador y un artista que sabía aquilatar el contexto de las producciones artísticas de los antiguos peruanos, como bien hasta aquí se ha podido analizar, sino que además coleccionaba estos mismos objetos, los cuales a su muerte, la ricca collezione di oggetti precolombiani e africani appartenuti a Eielson comprendente, oltre a ceramiche, sculture e strumenti di legno, anche molti tessuti preincaici, pasan al cuidado del Centri di Studi Jorge Eduardo Eielson. Se trata de objetos cuyo origen debería aclararse, así como el de otras colecciones privadas que sin duda tienen su propia procedencia.

Su postura lleva a una disyuntiva que también engloba a otros artistas peruanos. Con gran cuidado, llego hasta aquí. No es mi intención juzgar las elecciones de artistas como Jorge Eduardo, a quienes admiro y sigo. Incluso la propia evaluación que me tocó realizar desde la ficción me ha hecho tomar cada vez más conciencia de la complejidad del tema, que como vemos es esencial ahora.

En la curaduría realizada por Martha Canfield, se puede observar ese paralelo entre la posesión de esos objetos, y su correlato en la recreación y apropiación del mismo por parte del chamán prehispánico: "Le opere preincaiche giustapposte a quelle dell'artista creeranno un ideale ponte estetico concettuale tra passato e presente (...) Tra le opere che saranno esposte per la prima volta si segnalano una maschera rituale, un abito intero da cerimonia (Unku) e la Suite Paracas".

He tratado de contextualizar la elección de Jorge Eduardo en un viaje, para el que me he servido de diversas fuentes provenientes del Perú y del extranjero, del pasado, el presente y que remontan hacia el futuro, saliendo de la literatura para hincar los dientes en una realidad mucho más compleja. Revisar el tema me ha permitido (tanto en

\footnotetext{
15. El comunicado que citamos de esta exposición todavía se puede ver en http://www.arte.it/calendario-arte/firenze/mostra-eielson-artista-e-collezionista-3849. Por otro lado, esta exposición pone al corriente de las experiencias artísticas que tienen como correlato la exploración del legado prehispánico. Por tramos, Eielson ha recreado el tema prehispánico en sus poemarios más tardíos, además de en la novelística y los ensayos que se han citado hasta aquí (Celebración (Milán, 1990-1992) y Sin Título (Milán, 1994-1998), por ejemplo). Además, con su obra pictórica desde La Puerta de la Noche (1952), la cual siguió realizando hasta el final de sus días, ocurre lo mismo. En consecuencia, es posible afirmar lo que el propio Eielson aseguraba sobre la evolución, citando a Stephen Jay Gould: "la evolución no procede linealmente, unívocamente, ni con [...] rigidez [... ], sino que se manifiesta dando saltos, hacia delante y atrás, hacia arriba y abajo, incluso hacia los lados" (2004, p. 591).
} 
la ficción como fuera de ella, dentro de una visión totalmente estética a una enclavada en la arqueología, las leyes y las elecciones que toma el artista) descubrir no solo una problemática, sino sus diversas soluciones, las cuales tientan a mirar hacia las estrellas en busca de más respuestas.

No me basta la literatura después de esta exploración. También como Eduardo en la novela de 1971, voy en busca del Gran Traje de Seda y la original Venus Anadyomene ${ }^{16}$.

\section{Referencias}

Eielson, J. E. (2004). Arte poética. Lima, Perú: Pontificia Universidad Católica del Perú.

Eielson, J. E. (2010). Ceremonia comentada. Textos sobre arte, estética y cultura (1946-2005). Lima, Perú: Institut Français d'Études Andines.

Eielson, J. E. (2014). Primera muerte de María. Lima, Perú: Santuario.

Eielson artista e collezionista. (2013). Milano, Italia: Arte.it The map of art in Italy. http://www.arte. it/calendario-arte/firenze/mostra-eielson-artista-e-collezionista-3849.

Eielson, J. E. (2017). Puruchuco, por Jorge Eduardo Eielson. Lima, Perú: Vallejo and Company. Recuperado de http://www.vallejoandcompany.com/puruchuco-por-jorge-eduardo-eielson/

Gustavo Buntinx (Ed.). (2005). EPS Huayco. Documentos. Lima, Perú: Institut Français d'Études Andines.

Hastings, R. (julio, 2006). Un extranjero en todas partes. Libros \& Artes Revista de Cultura de la Biblioteca Nacional del Perú, (14-15), 25-26.

Hocquenghem, A.M. (1987). Iconografía mochica. Lima, Perú: Pontificia Universidad Católica del Perú.

Lauer, M. (1975) Szyszlo. Indagación y collage con ensayos de Javier Sologuren y E. A. Westphalen. Lima, Perú: Mosca Azul.

Lauer, M. (1989). El sitio de la literatura. Escritores y política en el s. XX peruano. Lima, Perú: Mosca Azul.

Lauer, M. (2007). Introducción a la pintura peruana del siglo XX. Lima, Perú: Universidad Ricardo Palma.

Meyer, Karl E. (1973). The plundered past. Nueva York: Atheneum.

Moro, C. (2002). Prestigio de amor. Lima, Perú: Pontificia Universidad Católica del Perú.

Mould de Pease, M. (noviembre, 2014). Aportes identitarios a la ruta del barroco cuzqueño. Un caso de restitución cultural religiosa. Tiempos. Revista de Historia y Cultura, 9, 63-94.

Pugliese Rossella (2010). Rapporto tra metafora e metonimia. Arcore, Italia: Tesionline. http:// www.tesionline.it/consult/brano.jsp?id=11444

Szyszlo, F. de. (julio, 2006). Eielson vive su época de gloria. Libros \& Artes Revista de Cultura de la Biblioteca Nacional del Perú, (14-15), 9-10.

Watson, P. \& Todeschini, C. (2007). The Medici conspiracy. Nueva York: Public Affairs.

16. No quiero dejar de invitar a la lectura de algunos extractos de mi novela Huaquero (Una Historia sobre la Historia), la cual ficcionaliza algunos temas aquí tratados en relación al patrimonio. Disponible en https:// huaquero.pressbooks.com/ 